\title{
Research Paper: The Effect and Durability of Hip and Core Exercises on Pain and Performance in Fe- males With Patellofemoral Pain Syndrome
}

\author{
Anita Raisi ${ }^{1}$ (D), Seyed Sadradin Shojaedin ${ }^{1 *}$ (D) Reza Habibi ${ }^{1}$ (]) \\ 1. Department of Biomechanic and Sport Injury, Faculty of Physical Education and Sport Sciences, Kharazmi University, Tehran, Iran.
}

CFtation Raisi A, Shojaedin SS, Habibi R. The Effect and Durability of Hip and Core Exercises on Pain and Performance in Females With Patellofemoral Pain Syndrome. Physical Treatments. 2020; 10(3):145-158. http://dx.doi.org/10.32598/ptj.10.3.431.1

: http://dx.doi.org/10.32598/ptj.10.3.431.1

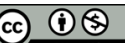

Article info:

Received: 21 Oct 2019

Accepted: 20 Jun 2020

Available Online: 01 Jul 2020

Keywords:

Patellofemoral pain syndrome, Core exercise, Hip exercise, Pain, Performance

\begin{abstract}
A B S T RA C T
Purpose: Patellofemoral Pain Syndrome (PFPS) is among the most frequent knee problems in active individuals. PFPS is a multifactorial syndrome with various treatments. This study compared the effects of two training methods of central stability and hip on pain and performance among women with PFPS.
\end{abstract}

Methods: In the present quasi-experimental study, 27 women with PPS aged between 20 and 30 years were selected as the statistical sample. The study subjects were randomly divided into three groups; core stability training, hip training, and controls. Two experimental groups performed the selected training in 8 weeks and three sessions per week. The Visual Analogue Scale (VAS) and Lower Extremity Functional Scale (LEFS) were used to measure pain and function in the study participants, respectively. The obtained data were analyzed using repeated-measures Analysis of Variance (ANOVA) and Multivariate Analysis of Covariance (MANCOVA) at a significance level of $\mathrm{P} \leq 0.05$.

Results: The MANCOVA results suggested a significant improvement in the measured variables in the experimental groups, compared to the controls $(\mathrm{P}<0.05)$; However, there was no significant difference concerning the effect and durability between the two experimental groups on the severity of pain $(\mathrm{P}<0.05)$; however, function significantly improved in the core stability training group $(\mathrm{P}<0.05)$.

Conclusion: The obtained data indicated the beneficial effects of both core and hip training on pain intensity and function in the explored female patients with PFPS. This effect could be due to the increased control and coordination of the knee's proximal joints. The comparison between the groups of the core and hip training highlighted that core training had a greater impact on the function than the hip.

\section{* Corresponding Author:}

Seyed Sadradin Shojaedin, $P h D$.

Address: Department of Biomechanic and Sport Injury, Faculty of Physical Education and Sport Sciences, Kharazmi University, Tehran, Iran

Phone: +98 (912) 5073897

E-mail:sa_shojaedin@yahoo.com 


\section{Highlights}

- The core exercise program could improve pain and performance in women with patella femoral pain syndrome

- The hip strengthening program could improve pain and performance in women with patella femoral pain syndrome

- There were not any difference between core exercise and hip strengthening programs regarding pain intensity and performance.

\section{Plain Language Summary}

The purpose of current study was investigate the effects of two exercise programs including core stability exercise and hip strengthening exercise on pain and performance of women with patella femoral pain syndrome. The result of study showed the both kind of exercise programs could improve pain and performance of women with patella femoral pain syndrome. However, there were not any difference between core exercise and hip strengthening programs regarding pain intensity and performance.

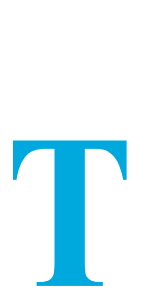

\section{Introduction}

he most frequent complication of the knee joint is the pain and dysfunction of the patellofemoral joint [1]. The reason for $20 \%$ to $40 \%$ of reference to medical centers and $10 \%$ of all reference to physiotherapy centers is reported to be knee pain. This syndrome is more prevalent in adolescents, and to a greater extent, in women [2]. Patellofemoral Pain Syndrome (PFPS) occurs during daily living activities, such as prolonged squat flexion of the knee or going up and down the stairs and is characterized by the pain limiting exercise participation. However, its cause remains undiscovered and controversial [3]. The degradation of the deep layer of the cartilage of the patellofemoral joint; excessive inward-outward mobility of the patella; change in the contact surface and the point of force entry due to the malalignment of the sacral-lumbar region of the patella; decreased quadriceps flexibility, and delayed onset of internal oblique muscle activity are among internal and external risk factors for the development of the syndrome $[4,5]$.

Witvrouw (2000) also added poor neuromuscular control of the proximal parts and weakness in the muscles around the hip to the causes of PFPS [6]. Review studies also reported reduced strength of hip muscles, such as abductors, external rotators, and extensors; as a result, patellar malalignment is addressed as causes of PFPS [7]. Yelvar (2015) argued that trunk and pelvic stability are essential for lower extremity movements. The transverse abdominal and multifidus muscles act as a co-contraction model and control the anterior pelvic tilt, i.e. believed to be associated with inward rotation and femoral adduction. Excessive inward rotation of the femur causes relative outward rotation in the tibia. This position enhances the Q angle; accordingly, it increases the contact surface of the outer part of the patella with the external condyle of the femur. Performing repetitive and continuous movements in this position destroys the cartilage under the patella. Therefore, the inability to control the trunk and pelvis affects lower extremity movements and the whole patellofemoral set [8].

Conservative treatment for the syndrome has conventionally been focused on the local factors of the patellofemoral joint and abnormal patellar movement on the trochlear groove [8]. Various studies have reported the accuracy of this topical treatment for knee pain [2]. However, studies on PFPS concluded that conservative therapies that emphasized proximal factors in addition to quadriceps muscle strengthening have improved pain in these patients $[9,10]$. The proximal factors of the patellofemoral joint, including muscle weakness around the hip and trunk, as well as abnormal trunk and hip movements, may significantly impact the development of patellofemoral pain [11]. In this regard, Fukuda et al. (2012) stated that adding a hip strengthening program to the conventional knee muscle strengthening program further improves pain and performance [12]. Khayyambashi et al. (2012) also documented that focusing the rehabilitation of PFPS on strengthening the abductor's muscles and hip rotator provides better outcomes [13].

Evidence suggests that hip exercises are effective in treating this syndrome; however, conflicting studies suggested that these exercises may fail to completely cure 
the syndrome. For example, after comparing hip exercises with traditional knee exercises, Dolak et al. (2011) demonstrated that hip exercises were not significantly superior to those focused locally on the knee [14]. Bolgla et al. (2011) also observed no significant difference between hip and knee strengthening exercises in a similar study [2]. Accordingly, perhaps other factors, including the proximal part of the hip (trunk) may play roles in causing this syndrome. It might be explained by the reduction in core stability due to alternations in muscle movement patterns that could lead to the trunk's excessive movement in different planes. As a result, it may affect the pelvis's condition and the mechanics of the lower extremity. Hip and trunk stabilizers may be activated sooner to compensate for trunk movement and control lower extremity position.

Decreased pre-contraction of the trunk and hip stabilizers may lead to excessive trunk displacement in the frontal plane. This process could also increase the load on the knee and secondarily may lead to disorders and injury in the knee due to the lack of control over the center of mass [15]. Previous research findings have suggested that it is useful to add a hip muscle strengthening program to the therapeutic protocol of patients with patellofemoral pain. However, no researcher has directly compared core stability training with hip muscle training or investigated and compared these training methods for this syndrome. Therefore, the current research aimed to compare the effects and durability of a hip and core stability training on pain, performance, and dynamic balance in women with PFPS.

\section{Materials and Methods}

The present study was a clinical trial with a pretest-post-test design. The statistical population of this study consisted of women with PFPS in Mashhad City, Iran. Among them, 27 women (Mean \pm SD height: $164.03 \pm 4.59 \mathrm{~cm}$ \& weight: $58.8 \pm 5.57 \mathrm{~kg}$ ) were selected as the statistical sample using a purposive sampling method. The study samples were then randomly divided into three groups of 9 individuals. The study inclusion criteria were as follows: a history of 6 months of pain in the anterior part of the knee or under the patella and around it, obtaining pain grade of 3-6 by the Visual Analogue Scale (VAS), experiencing the gradual onset of pain without a history of trauma, encountering pain (at least in two positions: going up and down the stairs, sitting for a long time with a bent knee, feeling pain in squat position $>90^{\circ}$, running, jumping, \& sitting with folded knees underneath), reporting knee pain in at least one of the performed tests, as follows: having pain dur- ing direct patellar pressure on the condyles of the femur when the knee is in full extension (Waldron's test), and experiencing pain in the patella when resistance is applied to the upper part of the patella during the isometric contraction of the quadriceps muscle (Clarke's Sign). The study exclusion criteria included a history of knee surgery, incomplete treatment sessions, receiving other treatment methods, experiencing trauma during the study, the aggravation of pain symptoms and encountering disability by performing study exercises, and objective evidence of osteoarthritis [16]. Besides, the research subjects provided informed consent forms to participate in the present study. The pre-test was then conducted on the study subjects. Then, the experimental groups 1 and 2 performed the selected exercises. Finally, post-test 1 was performed after 8 weeks of training, and post-test 2 was conducted four weeks after without training and based on the pre-test. In each training session, the study subjects warmed up for 10 minutes before starting the training; in the end, they performed the cool-down exercises for 10 minutes. The measurements were performed one day before the training, one day after the training, and after 4 weeks without training.

However, the control group received no specific rehabilitation treatment or exercise during this period, either professionally or recreationally. Exercises considered for the experimental group 1 included core stability exercises [8]; exercises selected for the experimental group 2 included hip exercises [17] (Appendix $1 \& 2$ ). The exercises were performed under the supervision of the researcher at the Tabrizi Sports Club in Mashhad City, Iran. The VAS was used to measure pain. The validity and reliability of this questionnaire were reported as 0.78 [18]. The Lower Extremity Functional Scale (LEFS) was used for measuring the study subjects' performance. This questionnaire has sufficient validity and reliability of 0.95 [19]. The obtained data were analyzed in SPSS using repeated-measures Analysis of Variance (ANOVA) and Multivariate Analysis of Covariance (MANCOVA) (intergroup comparison) at the significance level of $\mathrm{P} \geq 0.05$.

\section{Results}

Shapiro-Wilk's test was used to investigate the normal distribution of study variables. The relevant results suggested that all studied variables had a normal distribution. To compare the effect and durability of hip exercises and core stability on the pain and performance of the subjects, repeated-measures ANOVA was used at a significance level of $\mathrm{P} \leq 0.05$. The obtained data revealed the intragroup changes from pre-test to post-test phases. Hip exercises and core stability significantly affected the 
Table 1. Comparing pain and performance between the experimental groups 1 and 2 and the control group from the pre-test to posttests 1 and 2

\begin{tabular}{|c|c|c|c|c|c|}
\hline \multicolumn{2}{|c|}{ Group } & Phase & Mean $\pm S D$ & $\mathbf{F}$ & $\mathbf{P}$ \\
\hline \multirow{9}{*}{$\begin{array}{l}\text { Variable } \\
\text { level of pain }\end{array}$} & \multirow{3}{*}{ Experimental 1} & Pre-test & $6.3 \pm 1.49$ & \multirow{3}{*}{46.07} & \multirow{3}{*}{$0.001^{*}$} \\
\hline & & Post-test 1 & $4.5 \pm 1.43$ & & \\
\hline & & Post-test 2 & $4.4 \pm 1.17$ & & \\
\hline & \multirow{3}{*}{ Experimental 2} & Pre-test & $6.5 \pm 1.5$ & \multirow{3}{*}{21.44} & \multirow{3}{*}{$0.001^{*}$} \\
\hline & & Post-test 1 & $4.7 \pm 1.25$ & & \\
\hline & & Post-test 2 & $4.7 \pm 1.94$ & & \\
\hline & \multirow{3}{*}{ Control } & Pre-test & $6.6 \pm 1.17$ & \multirow{3}{*}{0.09} & \multirow{3}{*}{0.99} \\
\hline & & Post-test 1 & $6.6 \pm 1.07$ & & \\
\hline & & Post-test 2 & $6.6 \pm 0.84$ & & \\
\hline \multirow{9}{*}{ Performance } & \multirow{3}{*}{ Experimental 1} & Pre-test & $59.74 \pm 4.78$ & \multirow{3}{*}{30.1} & \multirow{3}{*}{$0.001^{*}$} \\
\hline & & Post-test 1 & $71.06 \pm 5.93$ & & \\
\hline & & Post-test 2 & $71.23 \pm 5.81$ & & \\
\hline & \multirow{3}{*}{ Experimental 2} & Pre-test & $58.12 \pm 4.15$ & \multirow{3}{*}{13.92} & \multirow{3}{*}{$0.001^{*}$} \\
\hline & & Post-test 1 & $62.69 \pm 5.72$ & & \\
\hline & & Post-test 2 & $63.02 \pm 5.54$ & & \\
\hline & \multirow{3}{*}{ Control } & Pre-test & $55.92 \pm 3.87$ & \multirow{3}{*}{0.46} & \multirow{3}{*}{0.63} \\
\hline & & Post-test 1 & $55.68 \pm 4.24$ & & \\
\hline & & Post-test 2 & $55.55 \pm 4.24$ & & \\
\hline
\end{tabular}

* Significance level was considered at $\mathrm{P}<0.05$.

PHYSICAL TREA $\$ MENTS

pain and performance of the study subjects at different research stages (Tables 1 and 2) $(\mathrm{P}<0.05)$; however, the related results were not significant in the control group.

MANCOVA at a significance level of $\mathrm{P} \leq 0.05$ was used to compare the effect and durability of hip exercises and core stability on the pain and performance of the study subjects (the pre-test scores of pain and performance were considered as covariate variables).

Table 3 presents that hip exercises and core stability significantly affected the pain and performance of the study subjects $(\mathrm{P}<0.05)$. However, it was impossible to determine the significant differences between the research groups; therefore, Fisher's Least Significant Difference (LSD) test was used to investigate the differences.

Table 4 demonstrates no significant difference between the two experimental groups regarding the intensity of pain after 8 weeks. However, there was a significant difference between the two experimental groups in terms of performance after 8 weeks of training.

Table 5 indicates a significant difference between the durability of hip exercises and core stability on pain and performance after 4 weeks of training $(\mathrm{P}<0.05)$. Howev$\mathrm{er}$, it was impossible to determine the significant differences between the research groups. Therefore, Fisher's LSD test was used to investigate the relevant difference.

Table 6 demonstrates a significant difference between the two experimental groups regarding the intensity of pain after 4 weeks without training. Nevertheless, there was a significant difference between the two experimental groups regarding the performance of individuals after 4 weeks without training. 
Table 2. Pairwise comparisons using the Bonferroni test on pain and performance variables

\begin{tabular}{|c|c|c|c|c|}
\hline Variable & Group & Stage & Mean Difference & $\mathbf{P}$ \\
\hline \multirow{7}{*}{ Pain } & & Pre-test, Post-test 1 & -1.8 & $0.001^{*}$ \\
\hline & Experimental group 1 & Pre-test, Post-test 2 & -1.9 & $0.001^{*}$ \\
\hline & & Post-test, 1-post-test 2 & -0.1 & 1.0 \\
\hline & & & & \\
\hline & & Pre-test, Post-test 1 & -1.8 & $0.004^{*}$ \\
\hline & Experimental group 2 & Pre-test, Post-test 2 & -1.8 & $0.002^{*}$ \\
\hline & & Post-test, 1-post-test 2 & 00 & 1.0 \\
\hline \multirow{7}{*}{ Performance } & & Pre-test, Post-test 1 & 11.32 & $0.001^{*}$ \\
\hline & Experimental group 1 & Pre-test, Post-test 2 & 11.49 & $0.001^{*}$ \\
\hline & & Post-test, 1-post-test 2 & 0.16 & 1.0 \\
\hline & & & & \\
\hline & & Pre-test, Post-test 1 & 4.57 & $0.02 *$ \\
\hline & Experimental group 2 & Pre-test-post-test 2 & 4.9 & $0.009^{*}$ \\
\hline & & Post-test, 1 -post-test 2 & 0.32 & 0.53 \\
\hline
\end{tabular}

\section{Discussion}

The present study results suggested no significant difference between the effect and durability of a hip training period and core stability on pain intensity in the explored women with PFPS. However, a significant difference was observed in both experimental groups 1 and 2 regarding pain intensity reduction after 8 weeks of training and 4 weeks without training, compared to the controls. The present study data were consistent with those of Yalfani et al. (2015), Rostami et al. (2015), Hoglund et al. (2018), and Khayyambashi et al. (2014). Yalfani et al. (2015) concluded that 8 weeks of hydrotherapy with and without tipping improved pain in women with PFPS [20]. They cited the positive effects of the water environment as the main possible reason for pain reduction. Rostami et al. compared three methods of training. These methods of core stability of the trunk included strengthening the extensor muscles, the external rotator of the hip, and quadriceps muscle. After 8 weeks of training, they observed a significant improvement in pain in all three groups. However, the effect of core stability exercises was more significant than the other two groups [21].

Regarding the effect of core stability and hip exercises, the present study data were consistent with those of Rostami and associates. However, no significant difference was observed in pain intensity between the two explored methods. This finding was inconsistent with that of the study by Rostami and colleagues. One possible reason for such data discrepancy could be the differences in the implemented training protocols of the two studies. The hip exercises used in the present study contained balance exercises, in addition to strengthening the external hip abductors and rotators. However, Rostami et al. (2015) only considered the strengthening of external abductors

Table 3. Comparing the effect of hip exercises and core stability on pain and performance in the study participants

\begin{tabular}{|c|c|c|c|c|c|}
\hline & & Sum of Squares & df & $\mathbf{F}$ & $\mathbf{P}$ \\
\hline \multirow{3}{*}{ Pain } & Covariate variable & 24.99 & 1 & 36.1 & 0.001 \\
\hline & & & & & \\
\hline & Group & 3.5 & 2 & 16.63 & 0.001 \\
\hline \multirow{3}{*}{ Performance } & Covariate variable & 253.1 & 1 & 12.63 & 0.001 \\
\hline & & & & & \\
\hline & Group & 704.64 & 2 & 17.58 & 0.001 \\
\hline
\end{tabular}


Table 4. Pairwise comparisons regarding pain and performance variables

\begin{tabular}{cccc}
\hline & & Mean Difference & Proup \\
\hline & & & 0.001 \\
Pain & Experimental 1-control & 1.89 & 0.001 \\
& Experimental 2-control & 1.83 & 0.86 \\
& Experimental1 -experimental 2 & 0.06 & 0.001 \\
Performance & Experimental 1-control & 12.65 & 0.01 \\
& Experimental 2-control & 5.44 & 0.001 \\
\hline
\end{tabular}

PHYSICAL TREA $₫$ MENTS

Table 5. Comparing the permanence of hip exercises and core stability on pain and performance

\begin{tabular}{cccccc}
\hline & & Sum of Squares & df & F & P \\
\hline \multirow{2}{*}{ Pain } & Covariate variable & 16.64 & 1 & 42.18 & 0.001 \\
& Group & 25.07 & 2 & 31.77 & 0.001 \\
Performance & Covariate variable & 247.39 & 1 & 12.97 & 0.001 \\
& Group & 738.55 & 2 & 19.36 & 0.001 \\
\hline
\end{tabular}

PHYSICAL TREA MENTS

and rotators of the hip. Haglund et al. also examined the effect of combined hip and core stability exercises on pain in patients with patellofemoral osteoarthritis. They, similar to the present study, observed a significant reduction in pain in the explored subjects [22]. Improving the strength of the central stabilizing muscles enhances muscle utilization, which consequently improves the proximal stability of the knee joint. Besides, improving the strength of central stabilizing muscles alters the strategies used by patients with PFPS [23]. Khayyambashi et al. compared the effect and duration of hip-knee exercises on pain in patients with PFPS. They observed a significant improvement in pain in both groups after 8 weeks of exercise. Furthermore, at a 6-month follow-up, this reduction in pain remained persistent in both experimental groups.

Comparing the two methods suggested that hip exercises provided more significant improvement and durability, compared to the knee exercises [24]. The leading cause of this syndrome was the weakness of the broad internal muscle and the late activation of this muscle, compared to the broad external muscle. Additionally, the leading cause of this syndrome is the regular kinematic disruption of the hip joint; the weakness of the external rotator and abductor muscles of the hip make the hip to approach

Table 6. Pairwise comparisons of pain and performance variables

\begin{tabular}{|c|c|c|c|}
\hline & & Mean Difference & $\mathbf{P}$ \\
\hline \multirow{3}{*}{ Pain } & Experimental 1-control & 2.03 & 0.001 \\
\hline & Experimental 2-control & 1.84 & 0.001 \\
\hline & Experimental 1-experimental 2 & 0.18 & 0.51 \\
\hline \multirow{3}{*}{ Performance } & Experimental 1-control & 12.98 & 0.001 \\
\hline & Experimental 2-control & 5.92 & 0.006 \\
\hline & Experimental 1 -experimental 2 & 7.06 & 0.001 \\
\hline
\end{tabular}


and rotate inwardly, which eventually leads to valgus in the knee. Valgus in the knee also makes the patella to protrude; therefore, causes the symptoms of PFPS [24]. The weakness of the external rotator and abductor muscles of the hip makes the hip to lose control of the frontal plate. Eventually, it generates misalignment in the lower extremity, especially the knees and patella. Besides, decreased core stability due to the changes in muscle movement patterns could lead to the excessive movement of the trunk in different planes. As a result, it may affect the pelvis's condition and the lower extremities' mechanics. In patients with PFPS, trunk stabilizers may be activated earlier to compensate for trunk movement and lower extremity position control. Decreased pre-contraction of the trunk and hip stabilizers may lead to the excessive displacement of the trunk in the frontal plane and increase the load on the knee. Decreased core stability and trunk and hip stabilizing synergists may secondarily lead to knee damage due to no control over the center of mass. Studies have suggested that some changes occur in the movement pattern of the muscles of the central region in patients. In these patients, e.g., the large and middle serine muscles begin to function later. Impaired motor control of the middle and large serine muscles could lead to pelvic prolapse, adduction, and the inward rotation of the hip and the larger vector of the valgus force in the knee, and changes in the knee joint; thus, feeling pain in the patellofemoral joint $[4,25]$.

Therefore, a possible reason for improving the patients' pain could be enhanced coordination and strength of the central stabilizing muscles and the hip. Besides, the present study data indicated a significant difference between the effect and durability of a hip training program and the core stability on the performance of the studied women with PFPS. Moreover, a significant improvement was observed in the performance of the core stability training group, compared to those of the hip exercise group. However, a significant increase in performance was observed in both experimental groups 1 and 2 after 8 weeks of training and 4 weeks without training, compared to the controls. The present study data were in line with those of the study by Yalfani et al. (2018), which compared 8 weeks of hydrotherapy with and without tipping in some subjects [20]. They measured the subjects' performance concerning the Kujala questionnaire; however, in the present study, the LEFS was used to evaluate the study participants' performance. However, the results of both studies were consistent. A reason for this consistency is the improvement of pain; this is because the reduction in pain in the subjects probably facilitated performing daily living activities in them; consequently, the studied subjects reported better performance. Rostami et al. (2017) also used a different method to evaluate performance in their study; however, they achieved similar results. They assessed performance using The Western Ontario and McMaster Universities Osteoarthritis Index (WOMAC) and after 8 weeks of training, they observed a significant improvement in the study subjects' performance [21]. In another consistent study, Khayyambashi et al. (2014) concluded that 8 weeks of hip and knee training improves performance; significant durability was also observed in the performance of individuals at the 6-month follow-up phase [24]. However, comparing two training groups indicated that hip exercises presented a more significant effect and durability, compared to the knee exercises.

A possible reason for further performance improvement in the group of core stability exercises, compared to the hip exercises could be a better improvement in trunk stability as well as an improvement in the trunk muscle activation pattern in the core stability training group. Improving the coordination and activity of these muscles in daily movements is necessary to stabilize the trunk and the lower extremity. Otherwise, the over-displacement of the trunk leads to unhealthy forces on the knee, like an inverted pendulum, and, in the long run, aggravates the pain of patients with PFPS [25]. Moreover, strengthening the muscles of the core stability of the trunk places the pelvis in the correct direction. Besides, better control is obtained over the pelvis by strengthening the muscles in the central area of the trunk; a proper femoral direction is maintained, and patellar bone contact with the ex

ternal condyle of the thigh is reduced. The lack of sufficient strength of the proximal parts of the knee leads to increased activity of tensor fasciae latae muscle due to enhanced proximity and the inward rotation of the hip; in turn, it increases the pressure on the external patella, and ultimately causes pain and decreased performance [26]. The used core stability exercises probably controlled the inward rotation and brought the thighs too close; consequently, they improved pelvic motion control. Such improvement may increase the use of external extensor and rotator muscles (large, middle, $\&$ small serine muscles). It reduces the activity of the tensor fasciae latae muscle, followed by stretching the external lateral retinaculum of the patella through the iliotibial band; eventually, it helps to place the patella in the right direction [19]. In the present study, the significant effect of central trunk stability exercises was due to the controlling role of core stability muscles on the trunk. As a result, it improved movement in the lower extremity as well as the efficiency of femoral movement in the hip joint. 


\section{Conclusion}

The obtained data indicated the beneficial effects of both core and hip training on pain intensity and function in the explored female patients with PFPS. This effect could be due to the increased control and coordination of the knee's proximal joints. The comparison between the groups of the core and hip training highlighted that core training had a greater impact on the function than the hip.

\section{Ethical Considerations}

\section{Compliance with ethical guidelines}

All ethical principles are considered in this article. The participants were informed about the purpose of the research and its implementation stages. They were also assured about the confidentiality of their information and were free to leave the study whenever they wished, and if desired, the research results would be available to them.

\section{Funding}

The present paper was extracted from the MSc. thesis of the first author, Department of Biomechanic and Sport Injury, Faculty of Physical Education and Sport Sciences of Kharazmi University.

\section{Authors' contributions}

All authors contributed equally in preparing all parts of the research

\section{Conflict of interest}

The authors declared no conflict of interest.

\section{Acknowledgments}

The subjects and all those who contributed to conducting this research are appreciated.

\section{References}

[1] Powers CM. Rehabilitation of patellofemoral joint disorders: A critical review. Journal of Orthopaedic \& Sports Physical Therapy. 1998; 28(5):345-54. [DOI:10.2519/ jospt.1998.28.5.345] [PMID]

[2] Bolgla LA, Boling MC. An update for the conservative management of patellofemoral pain syndrome: A systematic review of the literature from 2000 to 2010. International Journal of Sports Physical Therapy. 2011; 6(2):112-25. [PMID] [PMCID]

[3] Bolgla LA, Malone TR, Umberger BR, Uhl TL. Hip strength and hip and knee kinematics during stair descent in females with and without patellofemoral pain syndrome. Journal of Orthopaedic \& Sports Physical Therapy. 2008; 38(1):12-8. [DOI:10.2519/jospt.2008.2462] [PMID]

[4] Piva SR, Goodnite EA, Childs JD. Strength around the hip and flexibility of soft tissues in individuals with and without patellofemoral pain syndrome. Journal of Orthopaedic \& Sports Physical Therapy. 2005;35(12):793-801. [DOI:10.2519/ jospt.2005.35.12.793] [PMID]

[5] Waryasz GR, McDermott AY. Patellofemoral pain syndrome (PFPS): A systematic review of anatomy and potential risk factors. Dynamic Medicine. 2008; 7:9. [DOI:10.1186/14765918-7-9] [PMID] [PMCID]

[6] Witvrouw E, Lysens R, Bellemans J, Cambier D, Vanderstraeten G. Intrinsic risk factors for the development of anterior knee pain in an athletic population: A two-year prospective study. The American Journal of Sports Medicine. 2000; 28(4):480-9. [DOI:10.1177/03635465000280040701] [PMID]

[7] Prins MR, van der Wurff P. Females with patellofemoral pain syndrome have weak hip muscles: A systematic review. Australian Journal of Physiotherapy. 2009; 55(1):9-15 [DOI:10.1016/S0004-9514(09)70055-8] [PMID]

[8] Yılmaz Yelvar GD, Baltaci G, Tunay VB, Atay AÖ. The effect of postural stabilization exercises on pain and function in females with patellofemoral pain syndrome. Physiotherapy. 2015; 49(2):166-74. [DOI:10.1016/j.physio.2015.03.100] [PMID]

[9] Collins NJ, Bisset LM, Crossley KM, Vicenzino B. Efficacy of nonsurgical interventions for anterior knee pain Sports Medicine. 2012; 42(1):31-49. [DOI:10.2165/11594460000000000-00000] [PMID]

[10] Herrington L, Al-Sherhi A. A controlled trial of weightbearing versus non-weight-bearing exercises for patellofemoral pain. Journal of Orthopaedic \& Sports Physical Therapy. 2007; 37(4):155-60. [DOI:10.2519/jospt.2007.2433] [PMID]

[11] Powers CM, Bolgla LA, Callaghan MJ, Collins N, Sheehan FT. Patellofemoral pain: Proximal, distal, and local factors 2nd international research retreat. Journal of Orthopaedic \& Sports Physical Therapy. 2012; 42(6):A1-54. [DOI:10.2519/ jospt.2012.0301] [PMID]

[12] Fukuda TY, Melo WP, Zaffalon BM, Rossetto FM, Magalhães $\mathrm{E}$, Bryk FF, et al. Hip posterolateral musculature strengthening in sedentary women with patellofemoral pain syndrome: A randomized controlled clinical trial with 1-year follow-up. Journal of Orthopaedic \& Sports Physical Therapy. 2012; 42(10):823-30. [DOI:10.2519/jospt.2012.4184] [PMID]

[13] Khayambashi K, Mohammadkhani Z, Ghaznavi K, Lyle MA, Powers CM. The effects of isolated hip abductor and external rotator muscle strengthening on pain, health status, and hip strength in females with patellofemoral pain: A randomized controlled trial. Journal of Orthopaedic \& Sports Physical Therapy. 2012; 42(1):22-9. [DOI:10.2519/ jospt.2012.3704] [PMID] 
[14] Dolak KL, Silkman C, Medina McKeon J, Hosey RG, Lattermann C, Uhl TL. Hip strengthening prior to functional exercises reduces pain sooner than quadriceps strengthening in females with patellofemoral pain syndrome: A randomized clinical trial. Journal of Orthopaedic \& Sports Physical Therapy. 2011; 41(8):560-70. [DOI:10.2519/jospt.2011.3499] [PMID]

[15] Chevidikunnan MF, Al Saif A, Gaowgzeh RA, Mamdouh KA. Effectiveness of core muscle strengthening for improving pain and dynamic balance among female patients with patellofemoral pain syndrome. Journal of Physical Therapy Science. 2016; 28(5):1518-23. [DOI:10.1589/jpts.28.1518] [PMID] [PMCID]

[16] Zheng Y-L, Wang XF, Chen BL, Gu W, Wang X, Xu B, et al. Effect of 12-week whole-body vibration exercise on lumbopelvic proprioception and pain control in young adults with nonspecific low back pain. Medical Science Monitor. 2019; 25:443-452. [DOI:10.12659/MSM.912047] [PMID] [PMCID]

[17] Price DD, McGrath PA, Rafii A, Buckingham B. The validation of visual analogue scales as ratio scale measures for chronic and experimental pain. Pain. 1983; 17(1):45-56. [DOI:10.1016/0304-3959(83)90126-4] [PMID]

[18] Binkley JM, Stratford PW, Lott SA, Riddle DL. The Lower Extremity Functional Scale (LEFS): Scale development, measurement properties, and clinical application. North American Orthopaedic Rehabilitation Research Network Physical Therapy. 1999; 79(4):371-83. [PMID]

[19] Zahednejad S, Goharpey S, Farokhnia M. [Comparison of patellar taping versus patellar bracing with exercise therapy on pain and level of function in females with patellofemoral pain syndrome (Persian)]. Koomesh. 2017; 19(3):677-87. http:// koomeshjournal.semums.ac.ir/article-1-3335-en. $\mathrm{html}$

[20] Yalfani A, Mokhtari M, Gandomi F. [The effect of eight weeks of Aquatic therapy with patella taping on pain, motor function and unstable balance in women with the patellofemoral pain syndrome (Persian)]. Feyz. 2018; 22(3):30917. http:/ /feyz.kaums.ac.ir/article-1-3460-en.html

[21] Rostami zalani F, Falah A, Rahnama N. [Comparison of the effect of three combined training methods on pain and function in patients with patellofemoral pain syndrome (Persian)]. Qom University of Medical Science Journal. 2017 11(10):40-50. http://journal.muq.ac.ir/article-1-1043-en. html

[22] Hoglund LT, Pontiggia L, Kelly JD. A 6-week hip muscle strengthening and lumbopelvic-hip core stabilization program to improve pain, function, and quality of life in persons with patellofemoral osteoarthritis: A feasibility pilot study. Pilot and Feasibility Studies. 2018; 4:70. [DOI:10.1186/ s40814-018-0262-z] [PMID] [PMCID]

[23] Lephart SM, Fu FH. (2000). Proprioception and neuromuscular control in joint stability. Champaign: Human Kinetics. https://books.google.com/books?id=yT25tBsZbbYC\&dq

[24] Khayambashi K, Fallah A, Movahedi A, Bagwell J, Powers C. Posterolateral hip muscle strengthening versus quadriceps strengthening for patellofemoral pain: A comparative control trial. Archives of Physical Medicine and Rehabilitation. 2014; 95(5):900-7. [DOI:10.1016/j.apmr.2013.12.022] [PMID]
[25] Dierks TA, Manal KT, Hamill J, Davis IS. Proximal and distal influences on hip and knee kinematics in runners with patellofemoral pain during a prolonged run. Journal of Orthopaedic \& Sports Physical Therapy. 2008; 38(8):448-56. [DOI:10.2519/jospt.2008.2490] [PMID]

[26] Powers CM. The influence of altered lower-extremity kinematics on patellofemoral joint dysfunction: A theoretical perspective. Journal of Orthopaedic \& Sports Physical Therapy. 2003; 33(11):639-46. [DOI:10.2519/jospt.2003.33.11.639] [PMID] 
Appendix 1. Exercises used in the study Core stability exercises

\begin{tabular}{|c|c|c|c|}
\hline Weeks & Exercise & Set & Repeat/Time \\
\hline \multirow{10}{*}{$\begin{array}{c}\text { Week } 1 \\
\text { (sessions } 1 \text { to } 3 \text { ) }\end{array}$} & 1- Warming up with a stationary bicycle & 1 & 10 minutes \\
\hline & 2-Curl-ups & 2 & 10 repetitions \\
\hline & 3- Toe taps & 2 & 15 repetitions \\
\hline & 4- Plank & 2 & 20 seconds \\
\hline & 5- Side plank & 2 & 20 seconds \\
\hline & 6- Supine straight leg raising & 2 & 15 seconds \\
\hline & 7- Side-lying straight leg raising & 2 & 15 repetitions \\
\hline & 8- Prone knee flexion & 2 & 20 repetitions \\
\hline & 9- Draw foot circles in the supine position & 2 & 15 repetitions \\
\hline & 10- Draw foot circles lying sideways & 2 & 15 repetitions \\
\hline \multirow{10}{*}{$\begin{array}{c}\text { Week } 2 \\
\text { (sessions } 4 \text { to } 6 \text { ) }\end{array}$} & 1- Warming up with a stationary bicycle & 1 & 10 minutes \\
\hline & 2-Curl-ups & 2 & 15 repetitions \\
\hline & 3- Toe taps & 2 & 20 repetitions \\
\hline & 4- Plank & 2 & 25 seconds \\
\hline & 5- Side plank & 2 & 25 seconds \\
\hline & 6- Supine straight leg raising & 2 & 20 seconds \\
\hline & 7- Side-lying straight leg raising & 2 & 20 repetitions \\
\hline & 8- Prone knee flexion & 2 & 25 repetitions \\
\hline & 9- Draw foot circles in the supine position & 2 & 20 repetitions \\
\hline & 10- Draw foot circles lying sideways & 2 & 20 repetitions \\
\hline \multirow{12}{*}{$\begin{array}{c}\text { Week } 3 \\
\text { (sessions } 7 \text { to } 9 \text { ) }\end{array}$} & 1- Warming up with a stationary bicycle & 1 & 10 minutes \\
\hline & 2-Curl-ups & 2 & 15 repetitions \\
\hline & 3- Toe taps & 3 & 20 repetitions \\
\hline & 4- Plank & 2 & 25 seconds \\
\hline & 5- Side plank & 2 & 25 seconds \\
\hline & 6- Supine straight leg raising & 3 & 20 seconds \\
\hline & 7- Side-lying straight leg raising & 3 & 20 repetitions \\
\hline & 8- Prone knee flexion & 3 & 25 repetitions \\
\hline & 9- Draw foot circles in the supine position & 2 & 20 repetitions \\
\hline & 10- Draw foot circles lying sideways & 2 & 20 repetitions \\
\hline & 11- Prone cobra & 2 & 15 seconds \\
\hline & 12- Hip and knee extension in the crawling position & 2 & 15 repetitions \\
\hline
\end{tabular}




\begin{tabular}{|c|c|c|c|}
\hline Weeks & Exercise & Set & Repeat/Time \\
\hline \multirow{12}{*}{$\begin{array}{c}\text { Week } 4 \\
\text { (sessions } 10 \text { to } 12 \text { ) }\end{array}$} & 1- Warming up with a stationary bicycle & 1 & 10 minutes \\
\hline & 2-Curl-ups & 3 & 15 repetitions \\
\hline & 3- Toe taps & 3 & 20 repetitions \\
\hline & 4- Plank & 3 & 25 seconds \\
\hline & 5- Side plank & 3 & 25 seconds \\
\hline & 6- Supine straight leg raising & 3 & 20 seconds \\
\hline & 7- Side-lying straight leg raising & 3 & 20 repetitions \\
\hline & 8- Prone knee flexion & 3 & 25 repetitions \\
\hline & 9- Draw foot circles in the supine position & 3 & 20 repetitions \\
\hline & 10- Draw foot circles lying sideways & 3 & 20 repetitions \\
\hline & 11- Prone cobra & 2 & 15 seconds \\
\hline & 12- Hip and knee extension in the crawling position & 2 & 15 repetitions \\
\hline \multirow{12}{*}{$\begin{array}{c}\text { Week } 5 \\
\text { (sessions } 13 \text { to 15) }\end{array}$} & 1- Warming up with a stationary bicycle & 1 & 10 minutes \\
\hline & 2-Curl-ups & 3 & 20 repetitions \\
\hline & 3- Toe taps & 3 & 25 repetitions \\
\hline & 4- Plank & 3 & 30 seconds \\
\hline & 5- Side plank & 3 & 30 seconds \\
\hline & 6- Supine straight leg raising & 3 & 25 seconds \\
\hline & 7- Side-lying straight leg raising & 3 & 25 repetitions \\
\hline & 8- Prone knee flexion & 3 & 30 repetitions \\
\hline & 9- Draw foot circles in the supine position & 3 & 25 repetitions \\
\hline & 10- Draw foot circles lying sideways & 3 & 25 repetitions \\
\hline & 11- Prone cobra & 2 & 20 seconds \\
\hline & 12- Hip and knee extension in the crawling position & 2 & 20 repetitions \\
\hline \multirow{14}{*}{$\begin{array}{c}\text { Week } 6 \\
\text { (sessions } 16 \text { to } 18 \text { ) }\end{array}$} & 1- Warming up with a stationary bicycle & 1 & 10 minutes \\
\hline & 2- Curl-ups & 3 & 20 repetitions \\
\hline & 3- Toe taps & 3 & 25 repetitions \\
\hline & 4- Plank & 3 & 30 seconds \\
\hline & 5- Side plank & 3 & 30 seconds \\
\hline & 6- Supine straight leg raising & 3 & 25 seconds \\
\hline & 7- Side-lying straight leg raising & 3 & 25 repetitions \\
\hline & 8- Prone knee flexion & 3 & 30 repetitions \\
\hline & 9- Draw foot circles in the supine position & 3 & 25 repetitions \\
\hline & 10- Draw foot circles lying sideways & 3 & 25 repetitions \\
\hline & 11- Prone cobra & 3 & 20 seconds \\
\hline & 12- Hip and knee extension in the crawling position & 3 & 20 repetitions \\
\hline & 13- Weight bearing on one leg & 2 & 20 seconds \\
\hline & 14- Hip flexion sitting on the ball & 2 & 20 repetitions \\
\hline
\end{tabular}




\begin{tabular}{|c|c|c|c|}
\hline Weeks & Exercise & Set & Repeat/Time \\
\hline & 1- Warming up with a stationary bicycle & 1 & 10 minutes \\
\hline & 2- Curl-ups & 3 & 20 repetitions \\
\hline & 3- Toe taps & 3 & 30 repetitions \\
\hline & 4- Plank & 3 & 30 seconds \\
\hline & 5- Side plank & 3 & 30 seconds \\
\hline & 6- Supine straight leg raising & 3 & 30 seconds \\
\hline & 7- Side-lying straight leg raising & 3 & 30 repetitions \\
\hline \multirow[t]{15}{*}{$\begin{array}{c}\text { Week } 7 \\
\text { (sessions } 19 \text { to } 21 \text { ) }\end{array}$} & 8- Prone knee flexion & 3 & 30 repetitions \\
\hline & 9- Draw foot circles in the supine position & 3 & 30 repetitions \\
\hline & 10- Draw foot circles lying sideways & 3 & 30 repetitions \\
\hline & 11- Prone cobra & 3 & 25 seconds \\
\hline & 12- Hip and knee extension in the crawling position & 3 & 25 repetitions \\
\hline & 13- Weight bearing on one leg & 2 & 25 seconds \\
\hline & 14- Hip flexion sitting on the ball & 2 & 25 repetitions \\
\hline & 15- Weight-bearing forward and backward sitting on the ball & 2 & 15 repetitions \\
\hline & 1- Warming up with a stationary bicycle & 1 & 10 minutes \\
\hline & 2-Curl-ups & 3 & 20 repetitions \\
\hline & 3- Toe taps & 3 & 30 repetitions \\
\hline & 4- Plank & 3 & 30 seconds \\
\hline & 5- Side plank & 3 & 30 seconds \\
\hline & 6- Supine straight leg raising & 3 & 30 seconds \\
\hline & 7- Side-lying straight leg raising & 3 & 30 repetitions \\
\hline \multirow{9}{*}{$\begin{array}{c}\text { Week } 8 \\
\text { (sessions } 22 \text { to } 24 \text { ) }\end{array}$} & 8- Prone knee flexion & 3 & 30 repetitions \\
\hline & 9- Draw foot circles in the supine position & 3 & 30 repetitions \\
\hline & 10- Draw foot circles lying sideways & 3 & 30 repetitions \\
\hline & 11- Prone cobra & 3 & 30 seconds \\
\hline & 12- Hip and knee extension in the crawling position & 3 & 30 repetitions \\
\hline & 13- Weight bearing on one leg & 3 & 30 seconds \\
\hline & 14- Hip flexion sitting on the ball & 3 & 30 repetitions \\
\hline & 15- Weight-bearing forward and backward sitting on the ball & 3 & 20 repetitions \\
\hline & 16- Stairs-up on the Swiss ball & 2 & 20 repetitions \\
\hline
\end{tabular}


Appendix 2. Hip exercises

\begin{tabular}{|c|c|c|c|}
\hline Weeks & Exercise & Set & Repeat/Time \\
\hline \multirow{4}{*}{$\begin{array}{c}\text { Week } 1 \\
\text { (sessions } 1 \text { to 3) }\end{array}$} & 1- Warming up with a stationary bicycle & 1 & 10 minutes \\
\hline & 2- Hip abduction - standing & 2 & 10 repetitions \\
\hline & 3- Hip external rotator - standing & 2 & 10 repetitions \\
\hline & 4- Hip external rotator - seated & 2 & 10 seconds \\
\hline \multirow{4}{*}{$\begin{array}{c}\text { Week } 2 \\
\text { (sessions } 4 \text { to 6) }\end{array}$} & 1- Warming up with a stationary bicycle & 1 & 10 minutes \\
\hline & 2- Hip abduction - standing & 3 & 10 repetitions \\
\hline & 3- Hip external rotator - standing & 3 & 10 repetitions \\
\hline & 4- Hip external rotator - seated & 3 & 10 seconds \\
\hline \multirow{5}{*}{$\begin{array}{c}\text { Week } 3 \\
\text { (sessions } 7 \text { to 9) }\end{array}$} & 1- Warming up with a stationary bicycle & 1 & 10 minutes \\
\hline & 2- Hip abduction - standing & 3 & 10 repetitions \\
\hline & 3- Hip external rotator - standing & 3 & 10 repetitions \\
\hline & 4- Hip external rotator - seated & 3 & 10 seconds \\
\hline & 5- Balancing 2 feet - pad & 2 & 30 seconds \\
\hline \multirow{5}{*}{$\begin{array}{c}\text { Week } 4 \\
\text { (sessions } 10 \text { to } 12 \text { ) }\end{array}$} & 1- Warming up with a stationary bicycle & 1 & 10 minutes \\
\hline & 2- Hip abduction - standing & 3 & 10 repetitions \\
\hline & 3- Hip external rotator - standing & 3 & 10 repetitions \\
\hline & 4- Hip external rotator - seated & 3 & 10 seconds \\
\hline & 5- Balancing 2 feet - pad & 3 & 30 seconds \\
\hline \multirow{5}{*}{$\begin{array}{c}\text { Week } 5 \\
\text { (sessions } 13 \text { to 15) }\end{array}$} & 1- Warming up with a stationary bicycle & 1 & 10 minutes \\
\hline & 2- Hip abduction - standing & 3 & 10 repetitions \\
\hline & 3- Hip external rotator - standing & 3 & 10 repetitions \\
\hline & 4- Hip external rotator - seated & 3 & 10 seconds \\
\hline & 5- Balancing 1 feet - pad & 3 & 30 seconds \\
\hline \multirow{5}{*}{$\begin{array}{c}\text { Week } 6 \\
\text { (sessions } 16 \text { to } 18 \text { ) }\end{array}$} & 1- Warming up with a stationary bicycle & 1 & 10 minutes \\
\hline & 2- Hip abduction - standing & 3 & 10 repetitions \\
\hline & 3- Hip external rotator - standing & 3 & 10 repetitions \\
\hline & 4- Hip external rotator - seated & 3 & 10 seconds \\
\hline & 5- Balancing 1 feet - pad & 3 & 35 seconds \\
\hline
\end{tabular}




\begin{tabular}{|c|c|c|c|}
\hline Weeks & Exercise & Set & Repeat/Time \\
\hline \multirow{5}{*}{$\begin{array}{c}\text { Week } 7 \\
\text { (sessions } 19 \text { to 21) }\end{array}$} & 1- Warming up with a stationary bicycle & 1 & 10 minutes \\
\hline & 2- Hip abduction - standing & 3 & 10 repetitions \\
\hline & 3- Hip external rotator - standing & 3 & 10 repetitions \\
\hline & 4- Hip external rotator - seated & 3 & 10 seconds \\
\hline & 5- Balancing 1 feet - pad & 3 & 45 seconds \\
\hline \multirow{5}{*}{$\begin{array}{c}\text { Week } 8 \\
\text { (sessions } 22 \text { to 24) }\end{array}$} & 1- Warming up with a stationary bicycle & 1 & 10 minutes \\
\hline & 2- Hip abduction - standing & 3 & 10 repetitions \\
\hline & 3- Hip external rotator - standing & 3 & 10 repetitions \\
\hline & 4- Hip external rotator - seated & 3 & 10 seconds \\
\hline & 5- Balancing 1 feet - pad & 3 & 60 seconds \\
\hline
\end{tabular}

